\title{
Systems Neuroscience of Natural Behaviors in Rodents
}

\author{
${ }^{(D}$ Emily Jane Dennis, ${ }^{1}$ Ahmed El Hady, ${ }^{1}{ }^{\circledR}$ Angie Michaiel, ${ }^{2}{ }^{\circledR}$ Ann Clemens, ${ }^{3}$ Dougal R. Gowan Tervo, \\ ${ }^{\circ}$ Jakob Voigts, ${ }^{5}$ and ${ }^{-}$Sandeep Robert Datta ${ }^{6}$ \\ ${ }^{1}$ Princeton University and Howard Hughes Medical Institute, Princeton, New Jersey, 08540, ${ }^{2}$ University of Oregon, Eugene, Oregon, 97403-1254, \\ ${ }^{3}$ University of Edinburgh, Edinburgh, Scotland, EH8 9JZ, ${ }^{4}$ Janelia Research Campus, Ashburn, Virginia, 20147, ${ }^{5}$ Massachusetts Institute of \\ Technology, Cambridge, Massachusets, 02139, and ${ }^{6}$ Harvard University, Cambridge, Massachusets, 02115
}

Animals evolved in complex environments, producing a wide range of behaviors, including navigation, foraging, prey capture, and conspecific interactions, which vary over timescales ranging from milliseconds to days. Historically, these behaviors have been the focus of study for ecology and ethology, while systems neuroscience has largely focused on short timescale behaviors that can be repeated thousands of times and occur in highly artificial environments. Thanks to recent advances in machine learning, miniaturization, and computation, it is newly possible to study freely moving animals in more natural conditions while applying systems techniques: performing temporally specific perturbations, modeling behavioral strategies, and recording from large numbers of neurons while animals are freely moving. The authors of this review are a group of scientists with deep appreciation for the common aims of systems neuroscience, ecology, and ethology. We believe it is an extremely exciting time to be a neuroscientist, as we have an opportunity to grow as a field, to embrace interdisciplinary, open, collaborative research to provide new insights and allow researchers to link knowledge across disciplines, species, and scales. Here we discuss the origins of ethology, ecology, and systems neuroscience in the context of our own work and highlight how combining approaches across these fields has provided fresh insights into our research. We hope this review facilitates some of these interactions and alliances and helps us all do even better science, together.

Key words: systems neuroscience; behavioral ecology; ethology; rodents; natural behavior

\section{Introduction}

In the 1970s, the nascent field of systems neuroscience was built on the framework of systems theory, especially cybernetics (Wiener, 1965) and functional systems theory (Anokhin, 1984). These approaches were holistic and heavily influenced by mathematics, focusing on hierarchies, dynamics, analytics, and computer simulations (Metzler and Arbib, 1977). To this day, the heavy interplay between theory, mathematics, and neurophysiological recordings continues to define the field. A common systems approach to behavior involves designing a task where an animal is trained to produce a response, such as press a lever or move their eyes, to a set of stimuli. This is far removed from naturally observed behaviors. How did this become common?

Typically, a task is designed to try to isolate a specific computation that an animal will repeat many times each day. One common experimental design is called the two-alternative forced choice. An animal looks or moves to the left or right after the stimulus, and they are rewarded based on a learned "rule" (e.g., go left if you heard more sounds on the left). Animals will complete tens to thousands of trials per day, and we can then use the wealth of data acquired from these tasks to model the behavior,

\footnotetext{
Received July 19, 2020; revised 0ct. 15, 2020; accepted 0ct. 20, 2020.

J.V. is a cofounder of Open Ephys. S.R.D. is a cofounder of Syllable Life Sciences, Abelian Therapeutics and Optogenix, Inc. The remaining authors declare no competing financial interests.

We thank Mae Guthman, Emily Mackavicius, Alain St. Pierre, Adam Calhoun, and Manuel Schottdorf for reading recommendations.

Correspondence should be addressed to Emily Jane Dennis at emilyjanedennis@gmail.com.

https://doi.org/10.1523/JNEUROSCI.1877-20.2020

Copyright ( 2021 the authors
}

using a mathematical formulation. A model might add together, for example, effects of sensory adaptation, the individual stimuli presented, the timing of those stimuli, and the "noisiness" of the animal's memory and perception. This allows precise quantification of multiple aspects of the computation under study, and can help identify neurobiological correlates of internal variables, such as the current "belief" of the animal as it progresses through each trial and across trials. High trial counts are necessary when constructing and comparing behavioral models: each model parameter must be fit to the data, and lots and lots of data points are required to decrease the error in parameter estimation to make well-founded comparisons.

The need for large datasets with many repeated trials of the same type becomes even more important if the end goal is to record and perturb neural circuits during the task, to identify how populations of neurons can support the computation under study, or identify key brain regions that support the response. Up until quite recently, we could only record from a few neurons at a time, and even today whole-nervous system imaging is rare, extremely difficult, and limited to a few species (Ahrens et al., 2013; Nguyen et al., 2016). Therefore, the ability to average over lots of stimulus presentations is crucial. Furthermore, many methods used (e.g., 2-photon imaging and electrophysiology) have historically required head-fixation of the animals to decrease movement or to allow use of large technologies that are too heavy to mount to a freely moving animal's head (Juczewski et al., 2020).

Using these techniques, systems neuroscience has made great progress in identifying neural signatures of task-related activity 
and documenting the effects of perturbations, providing insight into how neural populations can reflect the internal computations that animals perform. However, the benefits of careful control of stimulus delivery, repeated trial types, and large recording technologies come at a cost. Teaching animals artificial responsestimulus pairings usually takes weeks or months. Animals are often extremely restricted in their movement, and other aspects (e.g., motivational state or body movements) are often ignored. More and more studies are acknowledging the downsides of ignoring these aspects: even in head fixed-animals, "spurious" movements contribute to, and are often necessary for, interpreting neural activity during a task (Gilad et al., 2018; Musall et al., 2019; Stringer et al., 2019).

Recent advances in technology and analysis have removed many of the barriers that historically kept systems approaches largely limited to highly trained, head-restrained behavioral tasks, and there is a growing interest in more natural behaviors. Many have called for neuroscientists to draw more inspiration from ethology and behavioral ecology (Anderson and Perona, 2014; Gomez-Marin et al., 2014; Krakauer et al., 2017; A. E. Brown and de Bivort, 2018; Juavinett et al., 2018; Mobbs et al., 2018; Datta et al., 2019; Gomez-Marin, 2019; M. W. Mathis and Mathis, 2020; Parker et al., 2020). Here, we echo this sentiment but also note that ethology and behavioral ecology can in turn be improved by considering systems neuroscience. We will limit our remaining discussion by focusing on rodents, but we want to acknowledge similar efforts for other mammals (Ghazanfar and Hauser, 1999; Ulanovsky and Moss, 2007), birds (Nottebohm, 2005; Carr and Peña, 2016), fish (Krahe and Fortune, 2013; Mearns et al., 2020), and invertebrates (Hamood and Marder, 2014; Haberkern et al., 2019; López-Cruz et al., 2019; Sakurai and Katz, 2019).

\section{Ethology needs systems neuroscience}

Ethology is the study of natural behaviors. In a foundational manuscript, Nikolaas Tinbergen laid out four questions central to the discipline: causation (how does it work?), survival value (what is it for?), evolution (how did it evolve?), and ontogeny (how does it develop?) (Tinbergen, 1963). Neuroethology, the study of the neural basis of natural behavior, has long asked similar questions. In one of the first neuroethology texts, Ewing lists the major research areas in neuroethology: signal detection; signal localization; memory acquisition; storage and recall; motivation; coordination; and top-down control (Ewing, 1981). These are all active areas of study in both ethology and systems neuroscience today, yet the fields tackle these problems in different ways.

Ethologists have traditionally focused on "champion organisms" (Heiligenberg, 1991). These are animals that have superior capabilities that are linked to highly specialized neuronal structure, and animals will readily perform these behaviors in the laboratory (Heiligenberg, 1991).

For example, mosquitoes are champion human smellers (DeGennaro et al., 2013), and owls are champion auditory hunters (Konishi, 2003). This approach likely comes partially from history, as ethology grew out of zoology as a discipline, and from suitability. For each champion organism, the adaptive value of their champion behavior is clear: mosquitoes must find a blood source to reproduce, owls must hunt in the dark to survive. Also, as champions, they produce these behaviors readily and often, even in artificial laboratory conditions, allowing ethologists to tackle Tinbergen's other three questions in the laboratory. This has yielded great insights into the mechanisms of sensory processing (Konishi, 2003) and learning (Nottebohm, 2005) and the evolution of circuit organization (Sakurai and Katz, 2017).

Yet this approach also has its limits. Restricting ourselves to champion organisms makes it more difficult to generalize results and communicate across disciplinary and species boundaries. Model organisms may have been chosen for ease of use and to model human pathologies, but they are, arguably, also champions. Rats and mice are champion generalists, they exhibit a huge range of behavioral variability and the ability to adapt to almost any environment, no matter how wild or artificial: from the sewers of New York City, to grain silos, to the wilds, one can find rats and mice almost anywhere. Their flexibility makes them excellent study subjects, and using these organisms comes with a wealth of chemical, molecular, genetic, and neural tools that can decrease the time between behavioral observation and deciphering neural mechanisms. Many opportunities for investigation await: their natural behavioral repertoire is rich (Fig. 1), but underexplored (J. B. Calhoun, 1963; Crowcroft, 1966; Combs et al., 2018; Phifer-Rixey and Nachman, 2015).

The ethological approach can also be limited by the questions asked. Tinbergen himself acknowledged that "hunger, like, anger, fear, and so forth, is a phenomenon that can be known only by introspection. When applied to another species, it is merely a guess about the possible nature of the animal's subjective state." Systems neuroscience allows us to take Tinbergen's "guess[es] about... subjective state," which systems neuroscientists would call internal states or computations, and turn them into testable hypotheses. Through mathematical models of behavior, we can open new and exciting research areas for ethological examination.

\section{Behavioral ecology needs systems neuroscience}

Historically, behavioral ecology grew out of ethology, but it focuses more on Tinbergen's second two questions regarding the adaptive value and evolutionary history of a trait (J. M. McNamara and Houston, 2009). In practice, behavioral ecologists usually study the interaction between individuals and their environment, and they often assume that animals will behave optimally or will adapt to maximize fitness in a given environment (Simmons, 2014). Foraging, parental care, predator-prey interactions, sexual selection, and social behaviors, such as cooperation, are common foci of behavioral ecology research. Technically, behavioral ecology differs from ethology through its heavy dependence on mathematical models. Both fields rely on natural observations and laboratory experiments, but the heavy use of mathematics, computer simulation, and statistics allows behavioral ecologists to model behavior and its evolution (Davidson and Gordon, 2017; Goldshtein et al., 2020; Harpaz and Schneidman, 2020). This process is reminiscent of systems neuroscience's reliance on mathematical models and theory to drive experiments, which in turn drive more models and theories. These two fields also draw heavily from Marr (1983), and the search for algorithmic-level understanding inspires many within each of these disparate fields.

Behavioral ecology has given us insights into speciation, sexual selection, and mate choice (Lande, 1981); foraging (Charnov, 1976) and diet (Schoener, 1971); and cooperation (Reeve et al., 1998). However, behavioral ecologists generally do not examine the cognitive machinery that processes information, leaving open the question of how neural systems constrain decisionmaking under ecological conditions. Circuit-level insights could further constrain models of optimality, and place realistic natural bounds on how animals can maximize fitness, improving predictions and linking ecological models back to 

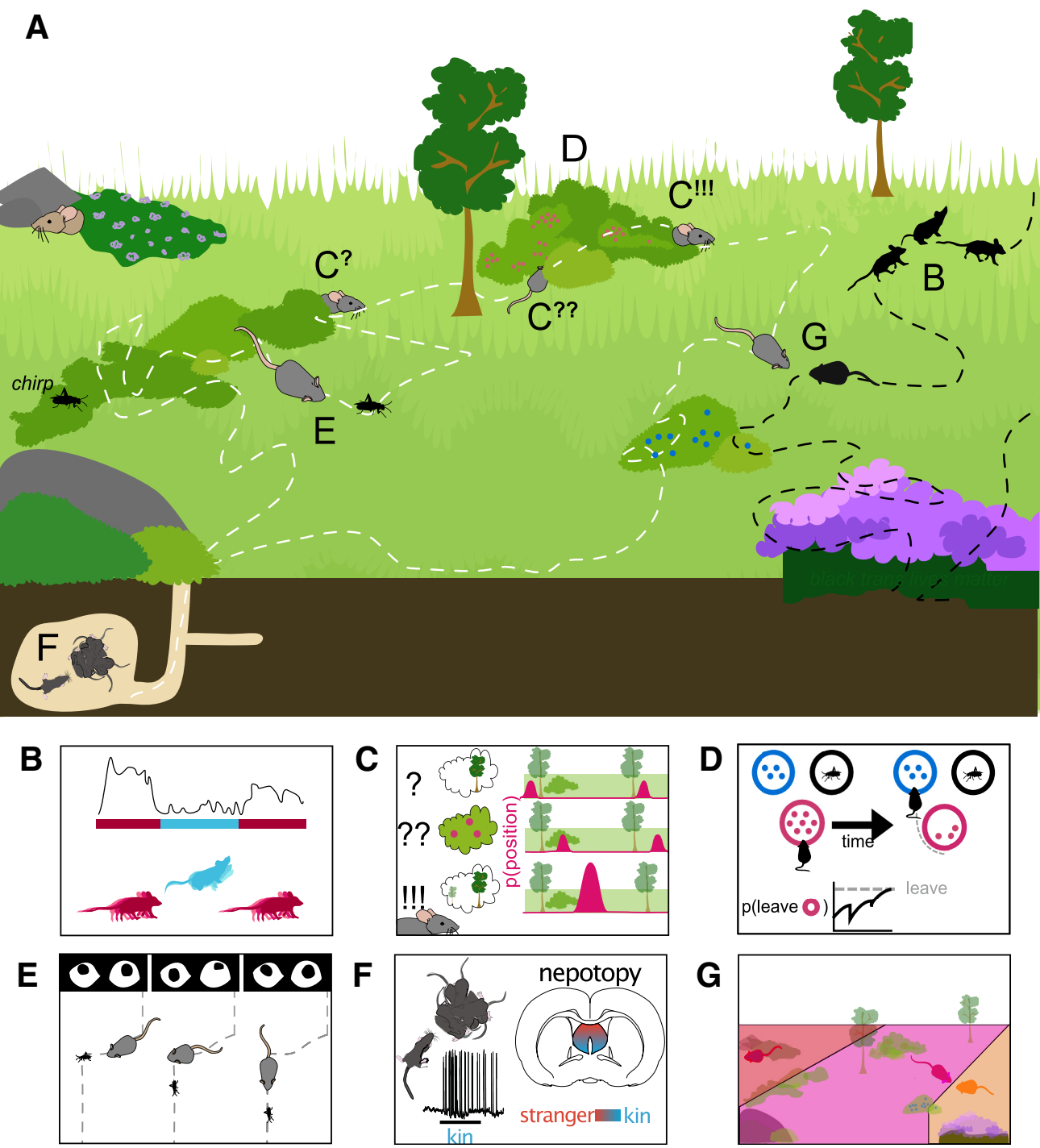

Figure 1. A day in the life of a few wild rodents. $A$, A diagrammed scene with dotted line "tracks" indicating the paths 2 mice could take throughout an imaginary day. Letters indicate connection to subsequent panels below. $\boldsymbol{B}$, Animal movements can be broken up into syllables (blue, pink in inset), and the Datta group identified context-dependent neural correlates for subsecond behavioral structure in the dorsolateral striatum. C, At any moment, the local visible world is limited; and cues, like landmarks, can be ambiguous. Voigts identifies "uncertain" path representations in the mouse retrosplenial cortex. $\boldsymbol{D}$, El Hady models the difficult choices animals must make when foraging, as they decide when to stay in an area with dwindling resources, and when to leave for other opportunities. $\boldsymbol{E}$, Michaiel uses head-mounted cameras to track eye movements during prey capture and uncover principles of visual processing. $\boldsymbol{F}$, Clemens identifies an organizing principle of the lateral septum by recording and watching rats interact with mom, siblings, and age-matched strangers. $\mathbf{G}$, Tervo identifies neural correlates of postural changes in behavior when animals interact with dominant or submissive rats during foraging.

Tinbergen's questions of causation and ontogeny, thus strengthening the bonds between ethology and ecology as well as systems neuroscience.

\section{New opportunities}

Why have these fields remained separate, although they ask similar questions and came into prominence around the same time? First, we must acknowledge that they have not remained entirely separate: Tinbergen himself discussed uniting physiology and ethology (Tinbergen, 1963), and some of the greatest successes of each of these fields were interdisciplinary. Mark Konishi was a paragon of neuroethology, but his auditory processing work leaned on systems-style modeling to isolate computations of individual neuron types in barn owls. Conversely, the famous systems neuroscience discovery of grid cells could not have happened without freely moving animals. These success stories required individuals who could speak to multiple audiences rather than the jargon of their subfield, highlight the similarities in goals and use tools that cross easily between disciplines.

Thanks to recent advances in machine learning, hardware miniaturization, and computation, there are new opportunities to combine systems and ethological approaches, to study and model complex behaviors in more natural conditions while recording movement, performing temporally specific perturbations, and recording from large numbers of neurons during freely moving behaviors. In the remainder of this review, we each provide an example from our own work, highlighting how combining these approaches can furnish fresh insights into the neurobiology of natural behaviors in rodents (Fig. $1 A$ ).

Identifying the grammar of behavior with machine learning and machine vision

The Datta laboratory studies how the brain uses naturalistic behavior to support cognition. But what is a meaningful 
behavioral output, and how do we find behaviors that are relevant to the animal, even if they do not have human-convenient descriptors? To address this question, the Datta laboratory developed a novel behavioral characterization technology called Motion Sequencing (MoSeq) (Fox et al., 2011; Wiltschko et al., 2015; Johnson et al., 2016; Datta, 2019; Datta et al., 2019). MoSeq combines three-dimensional machine vision and unsupervised machine learning approaches to instantiate the central hypothesis of ethology: that behavior is built from an identifiable sequence of stereotyped modules of action (Tinbergen, 1951; Simmons and Young, 1999). Here, unsupervised means that there is no human-annotated training data or ground-truth used to "teach" the algorithm what to find. Unsupervised learning is particularly useful here because mice are not humans, and finding regularities in the data that a human could not identify a priori is a particular strength of this technique. Using MoSeq, Datta and colleagues demonstrated that mouse behavior can indeed be segmented into a set of components, called "behavioral syllables." Each behavioral syllable is a brief and well-defined motif of 3D behavior that the brain places into sequences via definable transition statistics (or behavioral "grammar") to flexibly create complex patterns of action, either alone in an open field or in social groups (Fig. $1 B$ ).

To know how information from the outside world is encoded in the brain and transformed into these behaviors, they combined MoSeq with in vivo imaging of neural circuits in behaving animals using fiber photometry (Gunaydin et al., 2014). This approach identified context-dependent neural correlates for subsecond behavioral structure, and identified the dorsolateral striatum as a key node for implementing these behavioral sequences (Markowitz et al., 2018). Further, they have recently developed a closed-loop version of MoSeq to pulse optogenetic stimulation of dopamine during specific subsecond behavioral syllables, revealing rules that constrain naturalistic learning. These ongoing experiments demonstrate that MoSeq can serve as a quantitative prism useful for characterizing relationships between neural circuit activity and spontaneous behavior.

\section{New technology uncovers neural correlates of naturalistic navigation}

In Mark Hartnett's laboratory, Jakob Voigts is similarly looking to uncover how fine-grained behaviors, such as wall-following (Barnett, 1963), and individual left or right turn decisions (Dominiak et al., 2019) combine over longer timescales in goaldirected navigation behaviors, such as the search for rewards (Jackson et al., 2020). When animals navigate their natural environment, they are constantly faced with decisions about which paths to take. These decisions are part of a multilevel behavior: large-scale goals, such as finding food, mates, or avoiding predation, set the context for local pathfinding decisions, which are then executed by more fine-grained somatosensory and visually guided locomotion behavior. Understanding these decisions is a major component in understanding the computations that occur in natural behavior, yet much of what is known about rodent navigation in the laboratory context stems from experiments in which pathfinding decisions are simplified into mazes (Tolman, 1948; Olton et al., 1977; Crawley and Goodwin, 1980; Handley and Mithani, 1984) or largely featureless arenas with salient distal landmarks (Hall, 1936; O'Keefe and Dostrovsky, 1971; Morris, 1981) (Fig. 1C).

Voigts takes a hybrid approach: he trains mice to navigate to reward locations using a static pattern of landmarks that are only visible one at a time from close distances. This means that, at any given moment, mice only have access to incomplete local sensory information, but to successfully find rewards, they must integrate information as they move through the environment. Mice can solve such navigation tasks, echoing similar waypoint use in the wild (Stopka and Macdonald, 2003), and pointing to the existence of short-term memory processes that hold and update hypotheses about the animal's position (Kanitscheider and Fiete, 2017).

This work is newly possible. Recent advances, such as miniaturized implants, motor behavior tracking, and gaze tracking, bring a new level of control to freely moving animals while reducing the impact on their behavior. Conversely, virtual reality has opened up the behavioral space available for study with head-fixed methods, such as 2-photon imaging either through traditional (Dombeck et al., 2007; Dombeck and Reiser, 2012) or freely head-rotating (Voigts and Harnett, 2020) microscopes. Voigts developed this head-rotating 2-photon imaging method specifically to allow for subcellular imaging of dendritic activity as animals navigate through purpose-built environments.

After imaging retrosplenial cortex using this head-rotating 2photon microscope and freely moving electrophysiology, Voigts looked at events where animals had only seen a small part of the learned arena, leaving them uncertain of their position. This incomplete information state had a distinct neural representation, suggesting that decision-making during navigation is driven by an intermediate, probabilistic representation of position. This may include information about food sources, mates, or predators. In his own laboratory, Voigts plans to further extend this work to include more complex environments and will consider the longer time-scales at which environments are explored in natural settings. This approach could provide a window into the complex decision-making processes that rodents carry out in the wild.

\section{Foraging as a window into decision-making}

One important goal of navigation is to find food. In the wild, foraging engages multiple cognitive computations in addition to spatial decision-making: animals may plan their routes, learn of food distributions across spatiotemporal scales, and perform statistical inference of food availability (A. J. Calhoun and Hayden, 2015; Mobbs et al., 2018). Behavioral ecology examines the multiple ways by which decision-making occurs in the animal's ecological niche and the evolutionary pressures that lead to decisions in natural environments, but generally does not examine the cognitive machinery that processes information nor the neural systems that likely constrain decision-making under ecological conditions (Hills, 2006; G. J. Stephens et al., 2008). Systems neuroscience has made great progress in elucidating the neurobiological mechanisms of decision-making; but because this is typically studied by training animals to perform stereotyped behaviors under laboratory conditions, this does not describe how such decisions are performed in a natural environment, nor the ecological and evolutionary forces that shaped these processes (Fig. 1D).

Patch foraging (Charnov, 1976; J. McNamara, 1982; Kacelnik and Bernstein, 1988; Olsson, 2006) is a rich and flexible type of foraging where an animal may enter a patch of food, such as a berry bush, harvest resources, and then leave to search for another patch of food (D. W. Stephens, 2008). The animal's behavior can be quantified by how long it stays in the patch, how long it takes to get to another patch, the amount of food it has consumed, and the movement pattern between patches. The animal's reward rate can be computed by its food intake over time, 
and often one assumes the animal wants to maximize its reward rate. Typically, experimenters use this framework to predict how and when an animal leaves one patch for another. Patch foraging is a widely studied and long-standing problem in behavioral ecology (King, 1986; Marschall et al., 1989; Rodríguez-Gironés and Vásquez, 1997; Nonacs and Soriano, 1998; Rita and Ranta, 1998; F. Green, 2006; Raine et al., 2006; Zhang and Hui, 2014), and has implications for studies of decision-making, behavioral economics, and systems neuroscience (Kolling et al., 2012; Hayden and Walton, 2014; Shenhav et al., 2014; Constantino and Daw, 2015; Lottem et al., 2018; Mobbs et al., 2018; HallMcMaster and Luyckx, 2019).

El Hady and colleagues have described a theoretical and conceptual framework for studying naturalistic decision-making in the context of patch foraging, combining methodologies from systems neuroscience and insights from ecology (Davidson and El Hady, 2019; Kilpatrick et al., 2020). This provides a quantitative mathematical description, or formalism, for designing naturalistic laboratory experiments to study foraging as it unfolds over multiple spatial and temporal scales, going beyond trialbased structures. Moreover, by changing the complexity of the foraging environment, the formalism can accurately predict the changes in decision strategies that the animal adopts. The model proposed by El Hady and Davidson can also be extended to understand how an animal learns the structure of the foraging environment, and how the presence of other animals and of social information changes foraging behavior. This approach enables studying natural behaviors, such as foraging, in the same formal manner that trained behaviors are currently studied in systems neuroscience. In the future, it will be exciting to see how this work can inform experiments in natural-like environments while recording from neurons in freely moving animals. This work blends the ecological and systems neuroscience theoretical approaches, and uses the common language of modeling to bridge the interrelated fields of foraging ecology and decision neuroscience.

\section{Studying prey capture reveals principles of visual processing} Rats and mice are generalist foragers: although they are well known for eating grain and pantry items, invertebrates make up a large part of their diet where available (Sage, 1981). Even laboratory-raised animals will, with just a few days of exposure, efficiently stalk, capture, and eat live prey (Hoy et al., 2016). In Cris Niell's laboratory, Angie Michaiel took advantage of this strong drive to attack crickets, and used it to uncover new insights into a classic systems neuroscience problem: visual control (Fig. 1E).

Across animal species, eye movements are used to sample and acquire information about the external world. The pattern of eye movements varies based on the animal's particular goal (Yarbus, 1967). In foveate animals, such as humans and several other primate species, eye movements serve to center the visual scene over the retinal fovea, granting the viewer high-acuity vision for complex visual search functions, such as identifying and tracking behaviorally relevant visual stimuli. Importantly, however, a majority of vertebrate species lack a specialized fovea, and it is unclear how eye movements in afoveate animals are coordinated to actively localize and track moving visual objects.

Previous studies in afoveate animals, such as in freely moving rodents, have shown that eye movements largely serve to compensate for head movements (Wallace et al., 2013; Payne and Raymond, 2017; Meyer et al., 2018, 2020), consistent with the vestibulo-ocular reflex present in nearly all species (Straka et al., 2016). While such compensation can stabilize the visual scene during movement, it is not clear how this stabilization is integrated with the potential need to shift the gaze for behavioral goals during self-motion. In addition, because eye movements are minimized when the head is held in a fixed position by the experimenter (Payne and Raymond, 2017; Meyer et al., 2020; Michaiel et al., 2020), understanding the mechanisms of gaze control and active visual search benefits from studies in freely moving behaviors.

To this end, Michaiel and colleagues designed a system to synchronously record head and bilateral eye movements (similar to Wallace et al., 2013; Meyer et al., 2018, 2020) during prey capture. Prey capture is an ethologically relevant behavior that, importantly, requires the localization of a distinct object in visual space (Hoy et al., 2016). As previously shown, these studies revealed that the majority of eye movements compensate for head movements, thereby acting to stabilize the visual scene. During head turns, however, periods of stabilization are interspersed by noncompensatory saccades that abruptly shift gaze position. Analysis of eye movements relative to prey position shows that the saccades do not preferentially select a specific point in the visual scene. Rather, orienting movements are driven by the head, with the eyes following, to stabilize and recenter the gaze. These findings help relate eye movements in rodents to other species, and provide a foundation for studying active vision during ethological behaviors in the mouse. This work builds on the deep knowledge of visual processing from systems neuroscience, and applied cutting-edge systems technical approaches to a natural behavior.

\section{An organizing principle of the septum uncovered by watching rats interact with mom and siblings}

Although mice and rats may be efficient cricket-killers, people who work closely with them know they can also be incredibly sweet and can often be seen playing, tickling, and snuggling with each other (Cox and Rissman, 2011; Ishiyama and Brecht, 2016; Reinhold et al., 2019). In Michael Brecht's group, Ann Clemens' recent work lays a strong foundation for the study of kinship in neural systems research that she will further explore in her own laboratory (Clemens et al., 2020) (Fig. 1F).

Early work by Peter Hepper showed that rat pups recognize and prefer their siblings to nonsiblings at birth, but this changes to a nonsibling preference later in development (Hepper, 1983). In humans, affiliative experience toward kin is correlated with activity in the lateral septum (Moll et al., 2012), Building on these insights, Clemens found that lesions of the lateral septum, but not lesion of the cortex, abolished preference behavior in both young (sibling-preferring) and older (sibling-avoidant) rat pups.

To further probe how sibling preference behavior may be supported in the lateral septum, Clemens performed juxta-cellular and whole-cell patch-clamp recordings in the lateral septum of young, sibling-preferring pups and older, nonsibling preferring pups while providing kin- and nonkin stimuli. The stimuli consisted of ultrasonic vocalizations from sibling pups, nonsibling pups, the pup's mother, and nonmother adults, which were played during the electrophysiological recording. Neurons of the lateral septum responded to odor stimuli and vocalizations with changes in both action potential firing rates and subthreshold membrane potentials. Finally, when the researchers mapped the locations of the recorded neurons in the lateral septum, they found a topographic organization in which sibling- and motherresponsive neurons were located ventrally and nonsibling and nonmother odor-responsive neurons were located dorsally. The authors named this organization based on kinship "nepotopy." 
This work identifies a brain region necessary for kinship behavior and describes the topographic organization of this region. Like other topographies in the brain, including tonotopy and somatotopy, this work suggests that the brain may organize social relationships in an ordered fashion to support integration of sensory cues and select appropriate behavioral outputs. Complementary evidence comes from studies regarding social interactions in prairie voles (Williams et al., 1992; Walum and Young, 2018; Beery 2019) where $\mathrm{Ca}^{2+}$ imaging experiments identify neuronal ensembles with shared activity characteristics with pair-bonded partners versus unfamiliar vole approach behavior (Scribner et al., 2020). These and other emerging studies show how the examination of a natural, ethologically relevant behavior can uncover novel computations and neural organizational principles.

\section{Rat social dynamics yield insights into the neural basis of switching behaviors}

Individual rats' behaviors are constrained and promoted by their social interactions with their conspecifics (Grant, 1963; Blanchard et al., 1977). Exactly how the presence and actions of one or several animals in these social interactions induces or restricts the behavior of another is a central unanswered question in animal behavior (Porfiri, 2018). In Alla Karpova's laboratory, Gowan Tervo has tracked the movement and classified the actions of multiple interacting rats of known social ranks. In these experiments, individual rats' actions and locations in an arena depend on the locations and actions of other rats. Furthermore, these dependencies, as well as the duration and frequency of each rat's set of postures, are correlated with the rats' social ranks. These differences in pose frequency are dependent on the presence of conspecifics. In his own laboratory, Tervo is now using wireless recording and perturbation technologies to probe the neural basis of this behavior, with special focus on the role of the dorsal medial prefrontal cortex to switching in postural dynamics (Fig. 1G).

In conclusion, although each of the authors of this review studies a different subset of behavior, we share a strong, behavior-first foundation. We all closely observe our animals, many of us with careful posture tracking and modeling. Only then do we move on to designing experiments to uncover neural mechanisms underlying these behaviors, using techniques that allow our animals to move freely.

"Animal behavior lives by the wits, good will, and agreement of the scientists creating it. Current interest in animals is high, and powerful new techniques are available to establish the mechanisms, development, evolution, and function of behavior. Yet the coherence of the discipline is low, its conceptual center increasingly little more than a weighted average of new interests and old allegiances" (Timberlake, 1993). These words are just as true today as they were 27 years ago.

We believe now is a time to forge new alliances, and to grow as a field. We urge our colleagues to recognize these similarities in goals across fields, to be open to collaborations, and to freely share data, hardware designs, and code to facilitate interdisciplinary work and interactions. As others have recently pointed out (Pfaff et al., 2019), to continue and build on this tradition of interdisciplinary work will require collaboration and openness. The popularity of open source tracking (Machado et al., 2015; A. Mathis et al., 2018; Graving et al., 2019; Pereira et al., 2019; Ebbesen and Froemke, 2020; Karashchuk et al., 2020), automated behavioral annotation (Kabra et al., 2013; Wiltschko et al., 2015; Eyjolfsdottir et al., 2016; Hsu and Yttri, 2019; Graving and
Couzin, 2020), closed-loop behaviorally driven experimentation (Schweihoff et al., 2019; Forys et al., 2020; Nourizonoz et al., 2020), electrophysiology and calcium imaging analysis software (Pachitariu et al., 2016a,b; Chung et al., 2017; Buccino et al., 2018; Chaure et al., 2018; Giovannucci et al., 2019; Cantu et al., 2020), open source hardware (Siegle et al., 2017; J. Brown et al., 2018; Aharoni and Hoogland, 2019; Voigts et al., 2019), and open data (Kranstauber et al., 2011; Oh et al., 2014; Yatsenko et al., 2018; Zheng et al., 2018; Ruebel et al., 2019) are paving the way. These open resources will be crucial to allow researchers to link knowledge across disciplines, species, and scales. For example, someone studying a natural behavior with a working memory component may be able to record neural activity in a brain region during their natural behavior and compare it with data from a highly trained behavior, leading to either a synthesis across tasks or ideas for more experiments to uncover the source of differences between the results, for instance, by recording more of the behavior during the two-alternative forced choice task, or by restricting some of the variables in the natural scene where the adaptive value may be more obvious. One could build on a model developed from a two-alternative forced choice task and modify it to fit a more natural behavior, or use it to fit data across multiple species, improving the understanding of how a computation may have evolved. These are just a few of the exciting possibilities ahead.

In 1963, Tinbergen highlighted the need to identify the "fundamental identity of aims and methods" to unite fields and that "co-operation between all these workers is within reach, and the main obstacle seems to be the lack of appreciation of the fact that there is a common aim." Today, we feel the same. Together, we are a group of scientists with deep appreciation for the common aims across many disciplines, especially systems neuroscience, ecology, and ethology. We hope this review and the MiniSymposium that will follow facilitate some of these interactions and alliances and help us all do even better science, together.

\section{References}

Aharoni D, Hoogland TM (2019) Circuit investigations with open-source miniaturized microscopes: past, present and future. Front Cell Neurosci 13:141.

Ahrens MB, Orger MB, Robson DN, Li JM, Keller PJ (2013) Whole-brain functional imaging at cellular resolution using light-sheet microscopy. Nat Methods 10:413-420.

Anderson DJ, Perona P (2014) Toward a science of computational ethology. Neuron 84:18-31.

Anokhin PK (1984) Systems analysis of the integrative activity of the neuron (1974). Pavlov J Biol Sci 19:43-101.

Barnett SA (1963) The rat: a study in behavior. Chicago: University of Chicago.

Beery AK (2019) Frank Beach award winner: Neuroendocrinology of group living. Hormones and behavior 107:67-75.

Blanchard RJ, Blanchard DC, Takahashi T, Kelley MJ (1977) Attack and defensive behaviour in the albino rat. Anim Behav 25:622-634.

Brown AE, de Bivort B (2018) Ethology as a physical science. Nature Phys 14:653-657.

Brown J, Behnam R, Coddington L, Tervo DG, Martin K, Proskurin M, Kuleshova E, Park J, Phillips J, Bergs AC, Gottschalk A, Dudman JT, Karpova AY (2018) Expanding the optogenetics toolkit by topological inversion of rhodopsins. Cell 175:1131-1140.e11.

Buccino AP, Lepperød ME, Dragly SA, Häfliger P, Fyhn M, Hafting T (2018) Open source modules for tracking animal behavior and closed-loop stimulation based on Open Ephys and Bonsai. J Neural Eng 15:055002.

Calhoun AJ, Hayden BY (2015) The foraging brain. Curr Opin Behav Sci 5:24-31.

Calhoun JB (1963) The ecology and sociology of the Norway rat. Washington, DC: Department of Health, Education, and Welfare, Public Health Service. 
Cantu DA, Wang B, Gongwer MW, He CX, Goel A, Suresh A, Kourdougli N, Arroyo ED, Zeiger W, Portera-Cailliau C (2020) EZcalcium: open source toolbox for analysis of calcium imaging data. bioRxiv 893198. doi: 10.1101/2020.01.02.893198.

Carr CE, Peña JL (2016) Cracking an improbable sensory map. J Exp Biol 219:3829-3831.

Charnov EL (1976) Optimal foraging, the marginal value theorem. Theor Popul Biol 9:129-136.

Chaure FJ, Rey HG, Quiroga RQ (2018) A novel and fully automatic spikesorting implementation with variable number of features. J Neurophysiol 120:1859-1871.

Chung JE, Magland JF, Barnett AH, Tolosa VM, Tooker AC, Lee KY, Shah KG, Felix SH, Frank LM, Greengard LF (2017) A fully automated approach to spike sorting. Neuron 95:1381-1394.e6.

Clemens AM, Wang H, Brecht M (2020) The lateral septum mediates kinship behavior in the rat. Nat Commun 11:3161.

Combs M, Puckett EE, Richardson J, Mims D, Munshi-South J (2018) Spatial population genomics of the brown rat (Rattus norvegicus) in New York City. Mol Ecol 27:83-98.

Constantino SM, Daw ND (2015) Learning the opportunity cost of time in a patch-foraging task. Cogn Affect Behav Neurosci 15:837-853.

Cox KH, Rissman EF (2011) Sex differences in juvenile mouse social behavior are influenced by sex chromosomes and social context. Genes Brain Behav 10:465-472.

Crawley J, Goodwin FK (1980) Preliminary report of a simple animal behavior model for the anxiolytic effects of benzodiazepines. Pharmacol Biochem Behav 13:167-170.

Crowcroft P (1966) Mice all over. London: Foulis.

Datta SR (2019) Q\&A: understanding the composition of behavior. BMC Biol 17:44.

Datta SR, Anderson DJ, Branson K, Perona P, Leifer A (2019) Computational neuroethology: a call to action. Neuron 104:11-24.

Davidson JD, El Hady A (2019) Foraging as an evidence accumulation process. PLoS Comput Biol 15:e1007060.

Davidson JD, Gordon DM (2017) Spatial organization and interactions of harvester ants during foraging activity. J R Soc Interface 14:20170413.

DeGennaro M, McBride CS, Seeholzer L, Nakagawa T, Dennis EJ, Goldman C, Jasinskiene N, James AA, Vosshall LB (2013) orco mutant mosquitoes lose strong preference for humans and are not repelled by volatile DEET. Nature 498:487-491.

Dombeck DA, Reiser MB (2012) Real neuroscience in virtual worlds. Curr Opin Neurobiol 22:3-10.

Dombeck DA, Khabbaz AN, Collman F, Adelman TL, Tank DW (2007) Imaging large-scale neural activity with cellular resolution in awake, mobile mice. Neuron 56:43-57.

Dominiak SE, Nashaat MA, Sehara K, Oraby H, Larkum ME, Sachdev RN (2019) Whisking asymmetry signals motor preparation and the behavioral state of mice. J Neurosci 39:9818-9830.

Ebbesen CL, Froemke RC (2020) Automatic tracking of mouse social posture dynamics by 3D videography, deep learning and GPU-accelerated robust optimization. bioRxiv 109629. doi: 10.1101/2020.05.21.109629.

Ewing AW (1981) Neuroethology. Exp Physiol 66:548-549.

Eyjolfsdottir E, Branson K, Yue Y, Perona P (2016) Learning recurrent representations for hierarchical behavior modeling. arXiv: 1611.00094 . Available at https://arxiv.org/abs/1611.00094.

Forys BJ, Xiao D, Gupta P, Murphy TH (2020) Real-time selective markerless tracking of forepaws of head fixed mice using deep neural networks. eNeuro 7:ENEURO.0096-20.2020.

Fox E, Sudderth EB, Jordan MI, Willsky AS (2011) Bayesian nonparametric inference of switching dynamic linear models. IEEE Trans Signal Process 59:1569-1585.

Ghazanfar AA, Hauser MD (1999) The neuroethology of primate vocal communication: substrates for the evolution of speech. Trends Cogn Sci 3:377-384

Gilad A, Gallero-Salas Y, Groos D, Helmchen F (2018) Behavioral strategy determines frontal or posterior location of short-term memory in neocortex. Neuron 99:814-828.e7.

Giovannucci A, Friedrich J, Gunn P, Kalfon J, Brown BL, Koay SA, Taxidis J, Najafi F, Gauthier JL, Zhou P, Khakh BS, Tank DW, Chklovskii DB, Pnevmatikakis EA (2019) CaImAn an open source tool for scalable calcium imaging data analysis. eLife 8:e38173.
Goldshtein A, Handel M, Eitan O, Bonstein A, Shaler T, Collet S, Greif S, Medellín RA, Emek Y, Korman A, Yovel Y (2020) Reinforcement learning enables resource partitioning in foraging bats. Curr Biol 30:40964102.e6.

Gomez-Marin A (2019) Computational neuroscience needs theoretical ethology: correcting an anthropomorphic bias. PhilSci archive: 15877. Available at http://philsci-archive.pitt.edu/15877/.

Gomez-Marin A, Paton JJ, Kampff AR, Costa RM, Mainen ZM (2014) Big behavioral data: psychology, ethology and the foundations of neuroscience. bioRxiv 006809. doi: 10.1101/006809.

Grant EC (1963) An analysis of the social behaviour of the male laboratory rat. Behavior 21:260-281.

Graving JM, Couzin ID (2020) VAE-SNE: a deep generative model for simultaneous dimensionality reduction and clustering. bioRxiv 207993. doi: 10.1101/2020.07.17.207993.

Graving JM, Chae D, Naik H, Li L, Koger B, Costelloe BR, Couzin ID (2019) DeepPoseKit, a software toolkit for fast and robust animal pose estimation using deep learning. eLife 8:e47994.

Green R (2006) A simpler, more general method of finding the optimal foraging strategy for Bayesian birds. Oikos 112:274-284.

Gunaydin LA, Grosenick L, Finkelstein JC, Kauvar IV, Fenno LE, Adhikari A, Lammel S, Mirzabekov JJ, Airan RD, Zalocusky KA, Tye KM, Anikeeva P, Malenka RC, Deisseroth K (2014) Natural neural projection dynamics underlying social behavior. Cell 157:1535-1551.

Haberkern H, Basnak MA, Ahanonu B, Schauder D, Cohen JD, Bolstad M, Bruns C, Jayaraman V (2019) Visually guided behavior and optogenetically induced learning in head-fixed flies exploring a virtual landscape. Curr Biol 29:1647-1659.e8.

Hall CS (1936) Emotional behavior in the rat: III. The relationship between emotionality and ambulatory activity. In J Comp Psychol 22:345-352.

Hall-McMaster S, Luyckx F (2019) Revisiting foraging approaches in neuroscience. Cogn Affect Behav Neurosci 19:225-230.

Hamood AW, Marder E (2014) Animal-to-animal variability in neuromodulation and circuit function. Cold Spring Harb Symp Quant Biol 79:21-28.

Handley SL, Mithani S (1984) Effects of alpha-adrenoceptor agonists and antagonists in a maze-exploration model of "fear"-motivated behaviour. Naunyn Schmiedebergs Arch Pharmacol 327:1-5.

Harpaz R, Schneidman E (2020) Social interactions drive efficient foraging and income equality in groups of fish. eLife 9:e56196.

Hayden BY, Walton ME (2014) Neuroscience of foraging. Front Neurosci $8: 81$.

Heiligenberg W (1991) The neural basis of behavior: a neuroethological view. Annu Rev Neurosci 14:247-267.

Hepper PG (1983) Sibling recognition in the rat. Anim Behav 31:1177-1191.

Hills TT (2006) Animal foraging and the evolution of goal-directed cognition. Cogn Sci 30:3-41.

Hoy JL, Yavorska I, Wehr M, Niell CM (2016) Vision drives accurate approach behavior during prey capture in laboratory mice. Curr Biol 26:3046-3052

Hsu AI, Yttri EA (2019) B-SOiD: an open source unsupervised algorithm for discovery of spontaneous behaviors. bioRxiv 770271. doi: 10.1101/770271.

Ishiyama S, Brecht M (2016) Neural correlates of ticklishness in the rat somatosensory cortex. Science 354:757-760.

Jackson BJ, Fatima GL, Oh S, Gire DH (2020) Many paths to the same goal: balancing exploration and exploitation during probabilistic route planning. eNeuro 7:ENEURO.0536-19.2020.

Johnson MJ, Duvenaud D, Wiltschko AB, Datta SR, Adams RP (2016) Composing graphical models with neural networks for structured representations and fast inference. arXiv:1603.06277.

Juavinett AL, Erlich JC, Churchland AK (2018) Decision-making behaviors: weighing ethology, complexity, and sensorimotor compatibility. Curr Opin Neurobiol 49:42-50.

Juczewski K, Koussa JA, Kesner AJ, Lee JO, Lovinger DM (2020) Stress and behavioral correlates in the head-fixed method. bioRxiv 963371. doi: 10.1101/2020.02.24.963371.

Kabra M, Robie AA, Rivera-Alba M, Branson S, Branson K (2013) JAABA: interactive machine learning for automatic annotation of animal behavior. Nat Methods 10:64-67.

Kacelnik A, Bernstein C (1988) Optimal foraging and arbitrary food distributions: patch models gain a lease of life. Trends in Ecology \& Evolution 3:251-253. 
Kanitscheider I, Fiete I (2017) Emergence of dynamically reconfigurable hippocampal responses by learning to perform probabilistic spatial reasoning. bioRxiv 231159. doi: 10.1101/231159.

Karashchuk P, Rupp KL, Dickinson ES, Sanders E, Azim E, Brunton BW, Tuthill JC (2020) Anipose: a toolkit for robust markerless 3D pose estimation. bioRxiv 117325. doi: 10.1101/2020.05.26.117325.

Kilpatrick ZP, Davidson JD, El Hady A (2020) Normative theory of patch foraging decisions. bioRxiv 055558. doi: 10.1101/2020.04.22.055558.

King BJ (1986) Extractive foraging and the evolution of primate intelligence. Hum Evol 1:361-372.

Kolling N, Behrens TE, Mars RB, Rushworth MF (2012) Neural mechanisms of foraging. Science 336:95-98.

Konishi M (2003) Coding of auditory space. Annu Rev Neurosci 26:31-55.

Krahe R, Fortune ES (2013) Electric fishes: neural systems, behaviour and evolution. J Exp Biol 216:2363-2364.

Krakauer JW, Ghazanfar AA, Gomez-Marin A, MacIver MA, Poeppel D (2017) Neuroscience needs behavior: correcting a reductionist bias. Neuron 93:480-490.

Kranstauber B, Cameron A, Weinzerl R, Fountain T, Tilak S, Wikelski M, Kays R (2011) The Movebank data model for animal tracking. Environ Model Softw 26:834-835.

Lande R (1981) Models of speciation by sexual selection on polygenic traits. Proc Natl Acad Sci USA 78:3721-3725.

López-Cruz A, Sordillo A, Pokala N, Liu Q, McGrath PT, Bargmann CI (2019) Parallel multimodal circuits control an innate foraging behavior. Neuron 102:407-419.e8.

Lottem E, Banerjee D, Vertechi P, Sarra D, Lohuis MO, Mainen ZF (2018) Activation of serotonin neurons promotes active persistence in a probabilistic foraging task. Nat Commun 9:1000.

Machado AS, Darmohray DM, Fayad J, Marques HG, Carey MR (2015) A quantitative framework for whole-body coordination reveals specific deficits in freely walking ataxic mice. eLife 4:e07892.

Markowitz JE, Gillis WF, Beron CC, Neufeld SQ, Robertson K, Bhagat ND, Peterson RE, Peterson E, Hyun M, Linderman SW, Sabatini BL, Datta SR (2018) The striatum organizes 3D behavior via moment-to-moment action selection. Cell 174:44-58.e17.

Marr D (1983) Vision: a computational investigation into the human representation and processing of visual information. New York: Holt.

Marschall EA, Chesson PL, Stein RA (1989) Foraging in a patchy environment: prey-encounter rate and residence time distributions. Anim Behav $37: 444-454$

Mathis A, Mamidanna P, Cury KM, Abe T, Murthy VN, Mathis MW, Bethge M (2018) DeepLabCut: markerless pose estimation of user-defined body parts with deep learning. Nat Neurosci 21:1281-1289.

Mathis MW, Mathis A (2020) Deep learning tools for the measurement of animal behavior in neuroscience. Curr Opin Neurobiol 60:1-11.

McNamara J (1982) Optimal patch use in a stochastic environment. Theor Popul Biol 21:269-288.

McNamara JM, Houston AI (2009) Integrating function and mechanism. Trends Ecol Evol 24:670-675.

Mearns DS, Donovan JC, Fernandes AM, Semmelhack JL, Baier H (2020) Deconstructing hunting behavior reveals a tightly coupled stimulusresponse loop. Curr Biol 30:54-69.e9.

Metzler J, Arbib MA (1977) Preface. In: Systems neuroscience (Metzler J, ed). San Diego: Academic.

Meyer AF, Poort J, O’Keefe J, Sahani M, Linden JF (2018) A head-mounted camera system integrates detailed behavioral monitoring with multichannel electrophysiology in freely moving mice. Neuron 100:46-60.e7.

Meyer AF, O'Keefe J, Poort J (2020) Two distinct types of eye-head coupling in freely moving mice. bioRxiv 957712. doi: 10.1101/2020.02.20.957712.

Michaiel AM, Abe ET, Niell CM (2020) Dynamics of gaze control during prey capture in freely moving mice. bioRxiv 006817. doi: 10.1101/ 2020.03.25.006817.

Mobbs D, Trimmer PC, Blumstein DT, Dayan P (2018) Foraging for foundations in decision neuroscience: insights from ethology. Nat Rev Neurosci 19:419-427.

Moll J, Bado P, de Oliveira-Souza R, Bramati IE, Lima DO, Paiva FF, Sato JR, Tovar-Moll F, Zahn R (2012) A neural signature of affiliative emotion in the human septohypothalamic area. J Neurosci 32:12499-12505.

Morris RG (1981) Spatial localization does not require the presence of local cues. Learn Motiv 12:239-260.
Musall S, Kaufman MT, Juavinett AL, Gluf S, Churchland AK (2019) Singletrial neural dynamics are dominated by richly varied movements. Nat Neurosci 22:1677-1686.

Nguyen JP, Shipley FB, Linder AN, Plummer GS, Liu M, Setru SU, Shaevitz JW, Leifer AM (2016) Whole-brain calcium imaging with cellular resolution in freely behaving Caenorhabditis elegans. Proc Natl Acad Sci USA 113:E1074-E1081

Nonacs P, Soriano JL (1998) Patch sampling behaviour and future foraging expectations in Argentine ants, Linepithema humile. Anim Behav 55: 519-527.

Nottebohm F (2005) The neural basis of birdsong. PLoS Biol 3:e164.

Nourizonoz A, Zimmermann R, Ho CL, Pellat S, Ormen Y, Prévost-Solié C, Reymond G, Pifferi F, Aujard F, Herrel A, Huber D (2020) EthoLoop: automated closed-loop neuroethology in naturalistic environments. Nat Methods 17:1052-1059.

Oh SW, Harris JA, Ng L, Winslow B, Cain N, Mihalas S, Wang Q, Lau C, Kuan L, Henry AM, Mortrud MT, Ouellette B, Nguyen TN, Sorensen SA, Slaughterbeck CR, Wakeman W, Li Y, Feng D, Ho A, Nicholas E, et al. (2014) A mesoscale connectome of the mouse brain. Nature 508:207214.

O'Keefe J, Dostrovsky J (1971) The hippocampus as a spatial map: preliminary evidence from unit activity in the freely moving rat. Brain Res 34:171-175.

Olsson O (2006) Bayesian foraging with only two patch types. Oikos 112:285-297.

Olton DS, Collison C, Werz MA (1977) Spatial memory and radial arm maze performance of rats. Learn Motiv 8:289-314.

Pachitariu M, Steinmetz N, Kadir S, Carandini M, Harris K (2016a) Kilosort: realtime spike-sorting for extracellular electrophysiology with hundreds of channels. bioRxiv 061481. doi: 10.1101/061481.

Pachitariu M, Stringer C, Schröder S, Dipoppa M, Federico Rossi L, Carandini M, Harris KD (2016b) Suite2p: beyond 10,000 neurons with standard two-photon microscopy. bioRxiv 061507. doi: 10.1101/061507.

Parker PR, Brown MA, Smear MC, Niell CM (2020) Movement-related signals in sensory areas: roles in natural behavior. Trends Neurosci 43:581595.

Payne HL, Raymond JL (2017) Magnetic eye tracking in mice. eLife 6:e29222.

Pereira TD, Aldarondo DE, Willmore L, Kislin M, Wang SS, Murthy M, Shaevitz JW (2019) Fast animal pose estimation using deep neural networks. Nat Methods 16:117-125.

Pfaff D, Tabansky I, Haubensak W (2019) Tinbergen's challenge for the neuroscience of behavior. Proc Natl Acad Sci USA 116:9704-9710.

Phifer-Rixey M, Nachman MW (2015) Insights into mammalian biology from the wild house mouse Mus musculus. eLife 4:e05959.

Porfiri M (2018) Inferring causal relationships in zebrafish-robot interactions through transfer entropy: a small lure to catch a big fish. Animal Behavior Cognition 5:4.

Raine NE, Ings TC, Dornhaus A, Saleh N, Chittka L (2006) Adaptation, genetic drift, pleiotropy, and history in the evolution of bee foraging behavior. In: Advances in the study of behavior. San Diego: Academic.

Reeve HK, Emlen ST, Keller L (1998) Reproductive sharing in animal societies: reproductive incentives or incomplete control by dominant breeders? Behav Ecol 9:267-278.

Reinhold AS, Sanguinetti-Scheck JI, Hartmann K, Brecht M (2019) Behavioral and neural correlates of hide-and-seek in rats. Science 365:1180-1183

Rita H, Ranta E (1998) Stochastic patch exploitation model. Proc R Soc Lond B Biol Sci 265:309-315.

Rodríguez-Gironés MA, Vásquez RA (1997) Density-dependent patch exploitation and acquisition of environmental information. Theor Popul Biol 52:32-42

Ruebel O, Tritt A, Dichter B, Braun T, Cain N, Clack N, Davidson TJ, Dougherty M, Fillion-Robin JC, Graddis N, Grauer M, Kiggins JT, Niu L, Ozturk D, Schroeder W, Soltesz I, Sommer FT, Svoboda K, Ng L, et al. (2019) NWB:N 2.0: an accessible data standard for neurophysiology. bioRxiv523035. doi: 10.1101/523035.

Sage RD (1981) Wild mice. Mouse Biomed Res 1:39-90.

Sakurai A, Katz PS (2017) Artificial synaptic rewiring demonstrates that distinct neural circuit configurations underlie homologous behaviors. Curr Biol 27:1721-1734.e3. 
Sakurai A, Katz P (2019) Command or obey? Homologous neurons differ in hierarchical position for the generation of homologous behaviors. J Neurosci 39:6460-6471.

Schoener TW (1971) Theory of feeding strategies. Annu Rev Ecol Syst 2:369404.

Schweihoff JF, Loshakov M, Pavlova I, Kück L, Ewell LA, Schwarz MK (2019) DeepLabStream: closing the loop using deep learning-based markerless, real-time posture detection. bioRxiv 884478. doi: 10.1101/ 2019.12.20.884478.

Scribner JL, Vance EA, Protter DS, Sheeran WM, Saslow E, Cameron RT, Klein EM, Jimenez JC, Kheirbek MA, Donaldson ZR (2020) A neuronal signature for monogamous reunion. Proc Natl Acad Sci USA 117:1107611084.

Shenhav A, Straccia MA, Cohen JD, Botvinick MM (2014) Anterior cingulate engagement in a foraging context reflects choice difficulty, not foraging value. Nat Neurosci 17:1249-1254.

Siegle JH, López AC, Patel YA, Abramov K, Ohayon S, Voigts J (2017) Open Ephys: an open-source, plugin-based platform for multichannel electrophysiology. J Neural Eng 14:045003.

Simmons LW (2014) 25 years of behavioral ecology. Behav Ecol 25:1-3.

Simmons PJ, Young D (1999) Nerve cells and animal behavior. New York: Cambridge University Press.

Stephens DW (2008) Decision ecology: foraging and the ecology of animal decision making. Cogn Affect Behav Neurosci 8:475-484.

Stephens GJ, Johnson-Kerner B, Bialek W, Ryu WS (2008) Dimensionality and dynamics in the behavior of C. elegans. PLoS Comput Biol 4: e1000028.

Stopka P, Macdonald DW (2003) Way-marking behaviour: an aid to spatial navigation in the wood mouse (Apodemus sylvaticus). BMC Ecol 3:3.

Straka H, Zwergal A, Cullen KE (2016) Vestibular animal models: contributions to understanding physiology and disease. J Neurology 263 Suppl 1: S10-S23.

Stringer C, Pachitariu M, Steinmetz N, Carandini M, Harris KD (2019) High-dimensional geometry of population responses in visual cortex. Nature 571:361-365.

Timberlake W (1993) Animal behavior: a continuing synthesis. Annu Rev Psychol 44:675-708.
Tinbergen N (1951) The study of instinct. Oxford: Clarendon Press. Available at https://psycnet.apa.org/record/2004-16480-000.

Tinbergen N (1963) On aims and methods of ethology. Z Tierpsychologie 20:410-433.

Tolman EC (1948) Cognitive maps in rats and men. Psychol Rev 55:189208.

Ulanovsky N, Moss CF (2007) Hippocampal cellular and network activity in freely moving echolocating bats. Nat Neurosci 10:224-233.

Voigts J, Harnett MT (2020) Somatic and dendritic encoding of spatial variables in retrosplenial cortex differs during 2D navigation. Neuron 105:237-245.e4

Voigts J, Newman J, Wilson MA, Harnett M (2019) An easy-to-assemble, robust, and lightweight drive implant for chronic tetrode recordings in freely moving animals. bioRxiv 746651. doi: 10.1101/746651.

Wallace DJ, Greenberg DS, Sawinski J, Rulla S, Notaro G, Kerr JN (2013) Rats maintain an overhead binocular field at the expense of constant fusion. Nature 498:65-69.

Walum H, Young LJ (2018) The neural mechanisms and circuitry of the pair bond. Nat Rev Neurosci 19:643-654.

Wiener N (1965) Cybernetics: or, control and communication in the animal and the machine. Cambridge, MA: Massachusetts Institute of Technology.

Williams JR, Catania KC, Carter CS (1992) Development of partner preferences in female prairie voles (Microtus ochrogaster): the role of social and sexual experience. Horm Behav 26:339-349.

Wiltschko AB, Johnson MJ, Iurilli G, Peterson RE, Katon JM, Pashkovski SL, Abraira VE, Adams RP, Datta SR (2015) Mapping sub-second structure in mouse behavior. Neuron 88:1121-1135.

Yarbus AL (1967) Eye Movements and Vision. New York: Plenum Press.

Yatsenko D, Walker EY, Tolias AS (2018) DataJoint: a simpler relational data model. arXiv:1807.11104v1.

Zhang F, Hui C (2014) Recent experience-driven behaviour optimizes foraging. Anim Behav 88:13-19.

Zheng Z, Lauritzen JS, Perlman E, Robinson CG, Nichols M, Milkie D, Torrens O, Price J, Fisher CB, Sharifi N, Calle-Schuler SA, Kmecova L, Ali IJ, Karsh B, Trautman ET, Bogovic JA, Hanslovsky P, Jefferis GS, Kazhdan M, Khairy K, et al. (2018) A complete electron microscopy volume of the brain of adult Drosophila melanogaster. Cell 174:730-743.e22. 